\title{
Effect of Gradation and Particle Shape on Sand Properties as Coverage of Beach Soccer Ground - Details of a Patent
}

\section{${ }^{1}$ Seyed Ramin Haghighizade, ${ }^{2}$ Morteza Jiryaei Sharahi", ${ }^{1}$ Seyed Mahmood Mirhosseini, ${ }^{2}$ Maryam Mousavi}

${ }^{1}$ Civil Engineering Department, Arak Branch, Islamic Azad University, Arak, Iran. ${ }^{2}$ Civil Engineering Group, Qom University of Technology, Qom, Iran.

\begin{abstract}
Background. Beach soccer is one of the most well-known international sports in the world. The laws of the game were introduced by some associations and today they are covered by FIFA. There are also certain rules for the selection of beach soccer sand, but the specifications are too simple and rough. Thus, a wide range of sand types falls in the acceptable range of FIFA. Objectives. In this study, an investigation is conducted to identify the effective parameters of beach soccer sand that affect the acceptability and quality of sand. The aim of this study is to determine which type of sand is more in accordance with the expectations of beach soccer players. Methods. This study is based on the results of a survey on 10 players of the national beach soccer team of Iran. The questionnaire includes questions about different aspects of sand quality at a number of beach soccer grounds. The sand samples are consequently compared by considering their gradations and particle shapes. A number of recommendations are presented in order to select high-quality sand for the purpose of beach soccer ground coverage. Results. The results are examined using numerical simulations. Finally, after conducting several tests and survey and gathering regional data, a simple and reliable method for ranking sand types used in beach soccer ground coverage is presented. The method can accurately predict the score of each sand sample by using the input data of gradation test, roundness test, and regional data. The sand types are scored according to the level of the match. Conclusion. In this manner, the grounds of beach soccer can be standardized using the presented ranking method.
\end{abstract}

KEY WORDS: Beach Soccer, Sand Quality, Ranking Method, Gradation, Particle Shape.

\section{INTRODUCTION}

Beach soccer is one of the most well-known international sports in the world. This sport was incorporated into the FIFA structure in 2004 and the first Beach Soccer World Cup was held on Copacabana beach Brazil in 2005 (1). The ground surface of the beach soccer game is covered by sand. Some criteria for the selection of appropriate sand are specified by FIFA. These rules for selection of sand are too simple and rough; therefore, a wide range of sand types with different properties is acceptable with FIFA. For example, according to FIFA (2), some rules for the ground surface are:

The surface should be composed of sand that is level and free of pebbles, shells, and any other objects that could injure the players. For

*. Corresponding Author:

Morteza Jiryaei Sharahi

E-mail: jiryaei@qut.ac.ir 
international competitions, the sand must be fine and at least $40 \mathrm{~cm}$ deep. It must be sifted until suitable for play, and must not be rough or contain pebbles or any other dangerous elements; however, it must not be so fine as to cause dust to stick to the skin.

Because of this mode of sand selection, the sand types at different beach soccer grounds have different properties and the beach soccer players do not have similar conditions in the matches. Therefore, the authors have investigated the effective parameters for sand quality using a number of experimental and numerical tests. This study is mainly based on geotechnical methods and concepts. It comprises three steps: i) survey, ii) experimental and numerical tests, and ii) correlation between survey and tests data.

Granular material, like sand, consists of a large number of particles of different shapes and sizes. In the past, several researchers have studied the impact of the size and shape of the sand particles on the global behavior of sand sample. In this section, a number of researches related to this topic are reviewed.

Martins and Barboza studied grain-size properties of sand gravel marine deposits in Brazil. This study focuses mainly on the relationship between grain-size properties and the sedimentary environment. Gradation diagrams are presented for different sand samples (3).

Arasan et al. used image analysis method to determine the grain-size distribution. The effects of particle shape and volume computation techniques on grain-size distribution were also researched. The results indicate that the shape of particles significantly affects the grain-size distribution (4).

Han et al. studied the influence of particle size on soil strength. The soil strength was measured using pullout tests of geocells embedded in the soil. The test results indicate that different types of geocells show different relationships with relative particle size of the backfill and pullout resistance (5).

The maximum friction angle of a sand sample can be correlated with many parameters, such as grain-size distribution $(6,7)$. Kara et al. investigated the effect of particle size on the internal friction angle of sand. A method is presented to estimate the friction angle using particle-size distribution (8).

The effect of particle size on the mechanical resistance of sand was studied by McDowell and Bolton (9). It was observed that peak resistance is larger for well-graded sand but the ultimate resistance is more or less independent of the initial particle-size distribution.

Cho et al. investigated the effect of particle shape on packing density, stiffness, and strength of sand. Sphericity, roundness, and smoothness were studied in terms of the particle shape (10).

There are many other studies on the different aspects of sand behavior, such as:

- mechanical behavior of sand $(11,12)$

- compaction and swelling of sand (13-15)

- sand mixture (16)

- cemented sand (17-27)

- sand strength (28-30)

- frozen sand (31-33)

- sand liquefaction (34-37)

- There are also a few studies on sand used for covering sporting grounds. For example, Crum et al. studied the engineering properties of high sand-content soil used in golf putting greens and sport fields (38). They focus mostly on bearing capacity, porosity, and gradation of such soil. Some data were presented for a number of fields, but there was no clear conclusion.

- ASTM F2396-04 suggests some guidelines for the construction of high-performance sand-based root zones. In this standard, a number of limitations related to particle-size distribution and physical and chemical properties of sand-based root zones are specified (39).

- In earlier studies, no method for the evaluation or ranking of sand for its utilization to cover sporting ground surfaceespecially beach soccer ground surface-is presented. Therefore, the authors have decided to do a comprehensive study on sand properties to find an evaluation method for sand used to cover beach soccer grounds.

This study is conducted to investigate the effect of the gradation and shape of sand particles on the quality and acceptability of sand as beach soccer ground coverage. A simple and reliable method for ranking and selection of an appropriate sand type 
to cover beach soccer grounds and a minimum sand quality are suggested, keeping in mind the levels of beach soccer matches.

\section{MATERIALS AND METHODS}

Survey. In the first step, a survey is done, in which 10 beach soccer players of the Iranian national beach soccer team were interrogated about different aspects of sand quality at seven beach soccer grounds. The names of the beach soccer grounds and the average results of the survey are presented in Tables 1 and 2 .

The questionnaire has nine questions. Questions 1-8 are related to some unwanted properties of sand samples, such as excessive roughness (coarse sand), excessive fineness (sand that sticks to the players' skin), dust, early fatigue, quick reduction of ball speed, excessive unevenness of ground surface (ball detour), low stiffness of ground surface, and high stiffness of ground surface. Question 9 pertains to the overall acceptability of sand or sand quality. In response to the questions, the players allotted a score between 0.0 and 10.0 for each question.

It can be seen in Table 2 that the seven sand samples have different qualities from the points of view of the beach soccer players (Question 9). Any clear relation between the responses to Question 1-8 and the response to Question 9 (sand quality) is not observed. In fact, Question 9 is the overall result of Questions 1-8.

The validity of the questionnaire is evidenced by the fact that different aspects of sands acceptability are directly addressed. It this study, the split-half method is used to estimate the reliability of the questionnaire.

Table 1. List of beach soccer grounds

\begin{tabular}{lcc}
\hline & Stadium or Ground Name & Location \\
\hline Sample 1 & Shahrdari (City council) & Iran, Rasht, Roodsar \\
Sample 2 & Park-e-saheli (Beach Park) & Iran, Bushehr \\
Sample 3 & Port Dickson & Malaysia, Sepang \\
Sample 4 & Olympic Village & Thailand, Phuket \\
Sample 5 & National football academy & Iran Tehran \\
Sample 6 & Alghadir Park & Iran, Bandar Abbas \\
Sample 7 & Katara & Qatar, Doha \\
\hline
\end{tabular}

Table 2. The average results of the survey

\begin{tabular}{lccccccc}
\hline & Samp. 1 & Samp. 2 & Samp. 3 & Samp. 4 & Samp. 5 & Samp. 6 & Samp. 7 \\
\hline Q1: excessive roughness & 2.10 & 6.40 & 3.60 & 1.60 & 5.50 & 6.10 & 5.60 \\
Q2: excessive fineness & 3.10 & 3.10 & 6.00 & 8.55 & 4.90 & 3.80 & 4.60 \\
Q3: dust & 2.70 & 3.60 & 4.90 & 1.60 & 6.60 & 3.80 & 3.90 \\
Q4: early fatigue & 6.65 & 6.75 & 7.00 & 8.65 & 6.90 & 5.80 & 3.40 \\
Q5: ball speed reduction & 6.80 & 6.40 & 4.60 & 3.50 & 7.15 & 5.90 & 3.70 \\
Q6: unevenness & 6.30 & 6.15 & 6.60 & 3.50 & 7.05 & 6.50 & 4.80 \\
Q7: ground low stiffness & 6.60 & 5.80 & 7.50 & 4.85 & 5.95 & 4.90 & 5.60 \\
Q8: ground high stiffness & 2.50 & 3.80 & 4.10 & 2.80 & 1.45 & 6.30 & 5.40 \\
Q9: overall sand quality & 8.65 & 7.10 & 5.00 & 8.45 & 8.10 & 5.80 & 8.40 \\
\hline
\end{tabular}

Table 3. The reliablity of questinaires

\begin{tabular}{cccccccc}
\hline & Samp. 1 & Samp. 2 & Samp. 3 & Samp. 4 & Samp. 5 & Samp. 6 & Samp. 7 \\
\hline $\mathrm{r}$ & 0.993 & 0.890 & 0.949 & 0.991 & 0.982 & 0.855 & 0.895 \\
$\rho$ & 0.997 & 0.942 & 0.974 & 0.995 & 0.991 & 0.922 & 0.945 \\
\hline
\end{tabular}

* r: reliability, $\rho$ : modified reliability (Spearman-Brown formula)

\section{RESULTS}

Gradation Test. The gradation or sieve test is a basic geotechnical test for granular soil types, like sand. The gradation or size distribution has an important impact on the various properties of sand. Therefore, this test is selected to compare 
sand samples and to find a correlation between sand quality and its physical properties. The results of the gradation test for seven sand samples are shown in Table 4 and Figure 1. As can be seen in Table 4, some samples with approximately similar particle-size distributions demonstrate different sand qualities. For example, the gradation diagrams of Samples 1, 5, and 6 are relatively similar, but they have different sand qualities, according to Table 2 .

Table 4. Results of gradation test

\begin{tabular}{ccccccccc}
\hline $\operatorname{Dia}(10 \%)$ & $\operatorname{Dia}(20 \%)$ & $\operatorname{Dia}(30 \%)$ & $\operatorname{Dia}(40 \%)$ & $\operatorname{Dia}(50 \%)$ & $\operatorname{Dia}(60 \%)$ & $\operatorname{Dia}(70 \%)$ & $\operatorname{Dia}(80 \%)$ & $\operatorname{Dia}(90 \%)$ \\
\hline 0.079 & 0.100 & 0.124 & 0.149 & 0.176 & 0.200 & 0.224 & 0.249 & 0.274 \\
0.206 & 0.286 & 0.343 & 0.385 & 0.424 & 0.474 & 0.569 & 0.918 & 1.679 \\
0.186 & 0.247 & 0.331 & 0.483 & 0.650 & 0.793 & 0.944 & 1.167 & 1.641 \\
0.155 & 0.199 & 0.239 & 0.291 & 0.401 & 0.585 & 0.759 & 0.955 & 1.337 \\
0.099 & 0.135 & 0.165 & 0.187 & 0.204 & 0.218 & 0.233 & 0.250 & 0.275 \\
0.096 & 0.126 & 0.151 & 0.169 & 0.184 & 0.198 & 0.233 & 0.252 & 0.545 \\
0.182 & 0.218 & 0.248 & 0.283 & 0.333 & 0.412 & 0.530 & 0.684 & 0.889 \\
\hline
\end{tabular}

$* \operatorname{Dia}(10 \%)$ is the size that $10 \%$ of particles are finer.

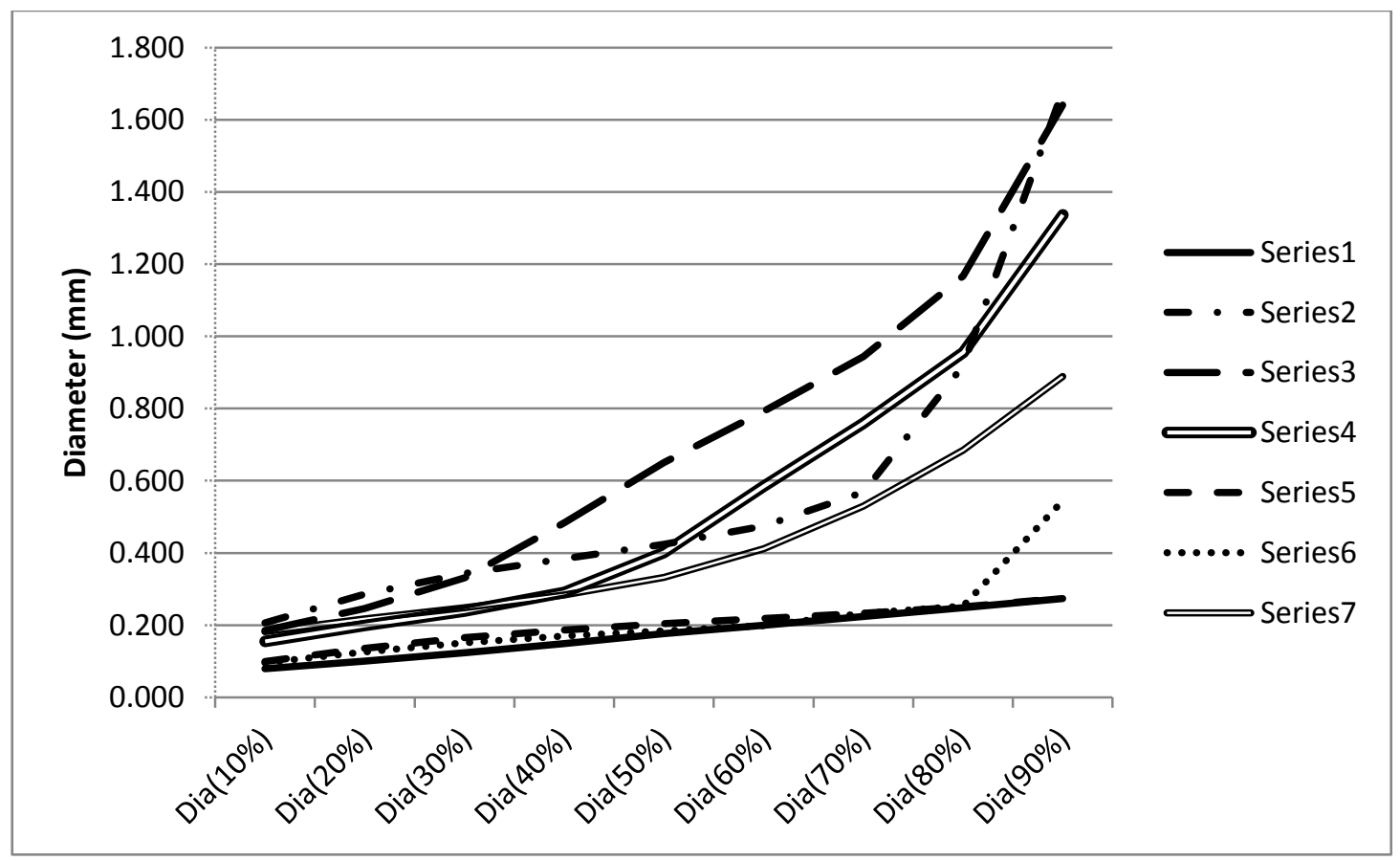

Figure 1. Results of gradation test

In this study, to compare the sand samples more efficiently, the gradation data is scaled so that $\mathrm{Dia}(10 \%)$ and $\mathrm{Dia}(90 \%)$ are reduced to zero (equation 1). In Equation 1, $\mathrm{X}=10,20, \ldots, 90$, and $i$ is column no. in gradation table $(i=1,2, \ldots$, 9). The "new" and "old" subscripts are related to Tables 5 and 4 respectively. The modified data is shown in Table 5. The data presented in the
Table 5 are depicted in Figures 2, 3, and 4. The diagrams in Figure 2 correspond to Samples 1, 4, 5 , and 7 , which have relatively high sand quality $(8.65,8.45,8.1$, and 8.4 respectively) according to Table 2. Figure 3 is related to Sample 2 with moderate sand quality (7.1) and the diagrams in Figure 4 are drawn using the data of Samples 3 and 6 , which have relatively low sand quality. 
Dia. $(X \%)_{\text {new }}=\mid$ Dia. $(X \%)_{\text {old }}-\left(\frac{9-i}{8}\right)$ Dia. $(10 \%)-\left(\frac{i-1}{8}\right)$ Dia. $(90 \%) \mid$

Comparing the scaled gradation diagrams in Figures 2, 3, and 4, it is obvious that there is a clear difference between the diagrams of highquality, moderate-quality, and low-quality sand. For high-quality sand (Sample 1, 4, 5, and 7), the particle distribution is represented by a smooth bell-shaped diagram with a maximum point in the middle region of horizontal axis. For moderate-quality sand sample, as shown in Figure 3, the maximum point moves to the right, while low-quality sand samples (Figure 4) do not have smooth bell-shaped diagrams.

Table 5. Modified gradation data

\begin{tabular}{ccccccccc}
\hline $\operatorname{Dia}(10 \%)$ & $\operatorname{Dia}(20 \%)$ & $\operatorname{Dia}(30 \%)$ & $\operatorname{Dia}(40 \%)$ & $\operatorname{Dia}(50 \%)$ & $\operatorname{Dia}(60 \%)$ & $\operatorname{Dia}(70 \%)$ & $\operatorname{Dia}(80 \%)$ & $\operatorname{Dia}(90 \%)$ \\
\hline 0.000 & 0.036 & 0.033 & 0.021 & 0.003 & 0.008 & 0.005 & 0.004 & 0.000 \\
0.000 & 0.266 & 0.403 & 0.493 & 0.550 & 0.579 & 0.566 & 0.386 & 0.000 \\
0.000 & 0.329 & 0.397 & 0.339 & 0.288 & 0.276 & 0.261 & 0.200 & 0.000 \\
0.000 & 0.342 & 0.470 & 0.513 & 0.462 & 0.345 & 0.271 & 0.197 & 0.000 \\
0.000 & 0.117 & 0.155 & 0.134 & 0.092 & 0.045 & 0.008 & 0.011 & 0.000 \\
0.000 & 0.171 & 0.273 & 0.359 & 0.425 & 0.474 & 0.462 & 0.483 & 0.000 \\
0.000 & 0.193 & 0.307 & 0.366 & 0.379 & 0.339 & 0.256 & 0.146 & 0.000 \\
\hline
\end{tabular}

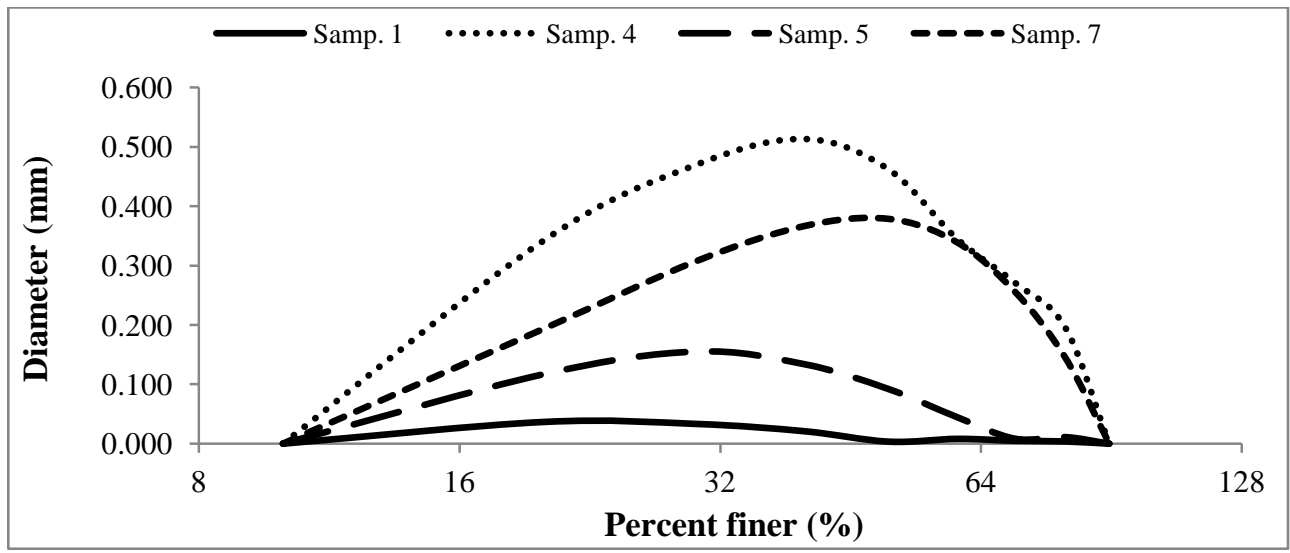

Figure 2. Scaled gradation diagrams for high quality sand samples

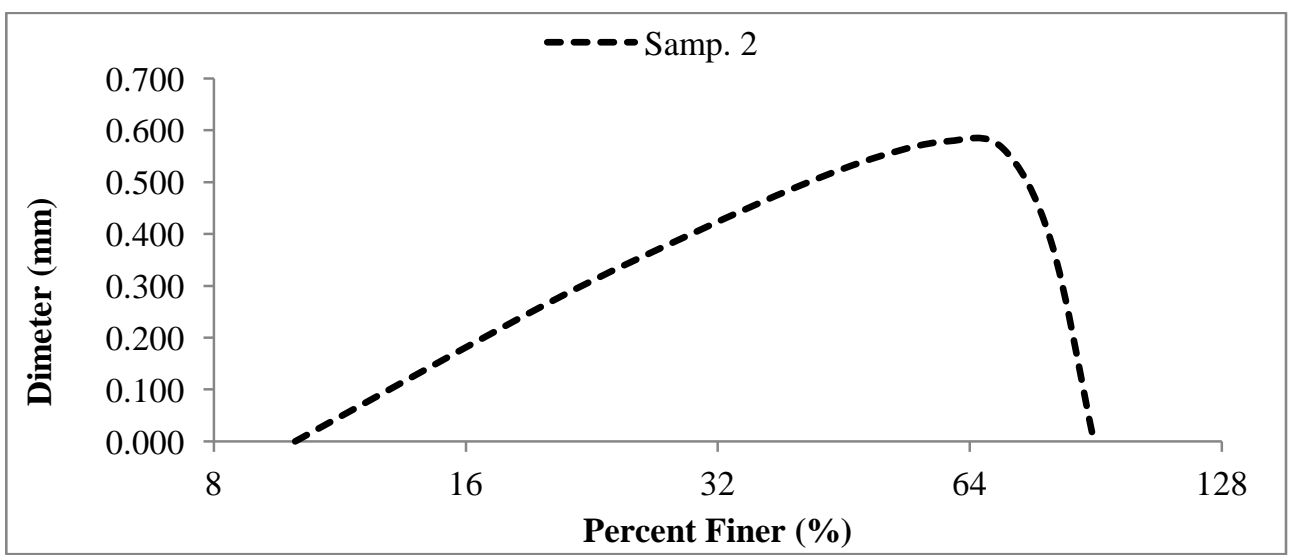

Figure 3. Scaled gradation diagram for moderate quality sand sample 


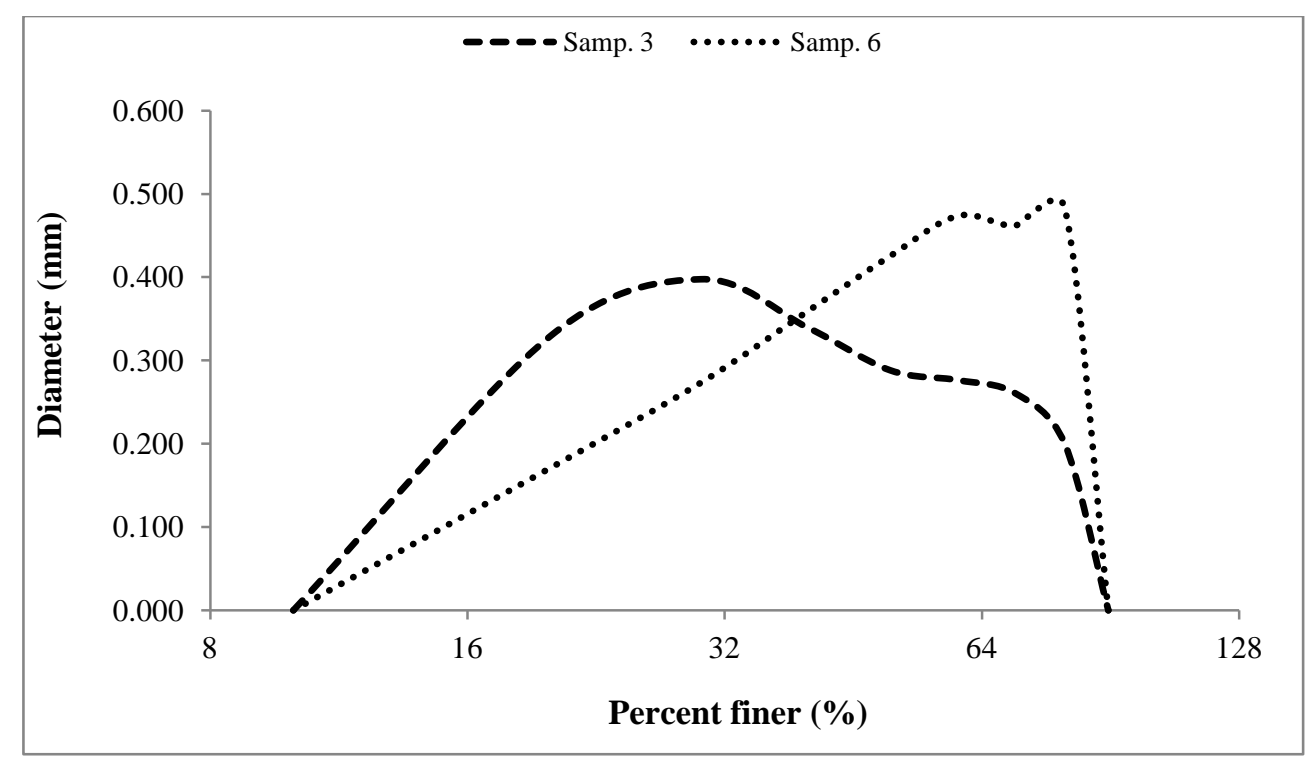

Figure 4. Scaled gradation diagrams for low quality sand samples

Particles shape. The shape of sand particles is another factor that can affects the properties of sand sample. In this study, particle shape is studied in terms of two concepts-roundness and sphericity. Roundness represents the degree of angularity of particles, while sphericity is related to overall shape of particles. The sphericity and roundness of sand particles are determined through visual judgment using microscopic images $(40,41)$. The main idea of these tests is illustrated in Figure 5. The microscopic images used in roundness and sphericity tests are shown in Figure 6.

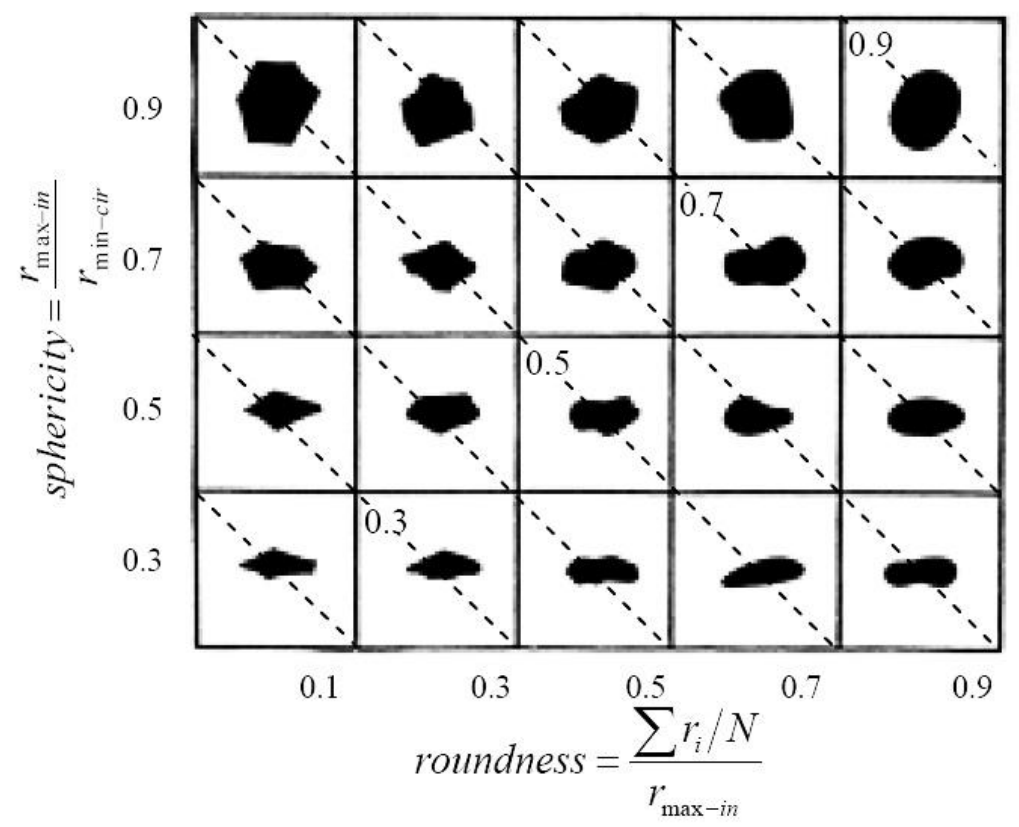

Figure 5. Sphericity $S$ and roundness $R$ chart. Modified from $(10,42)$ 


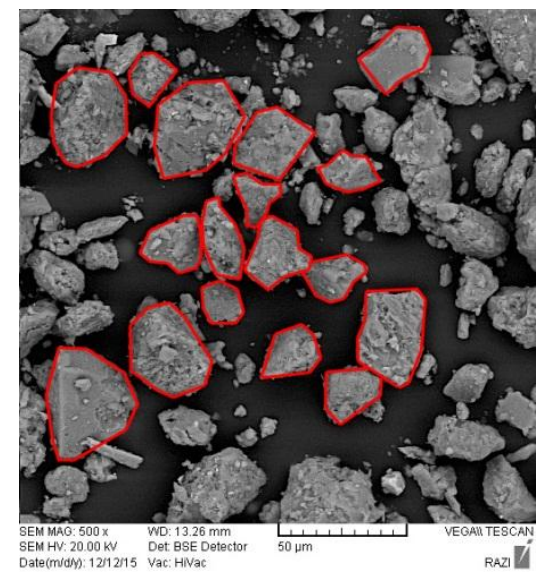

Sample 1

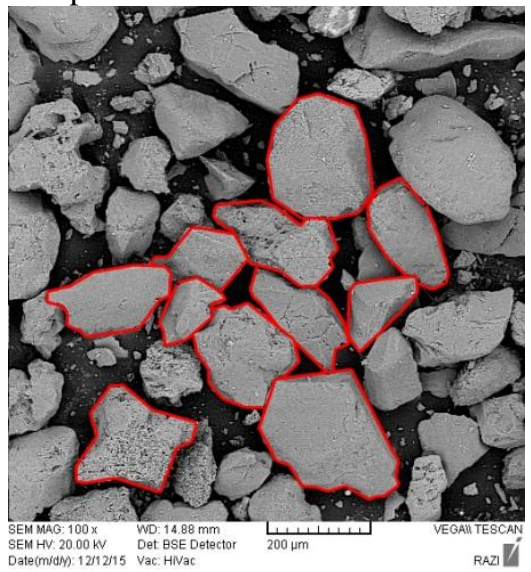

Sample 4

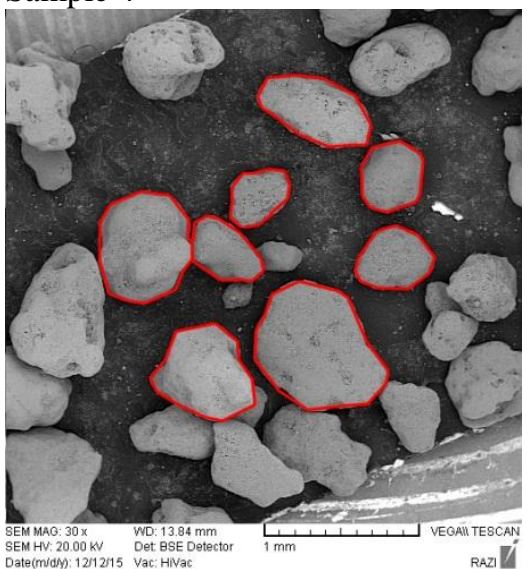

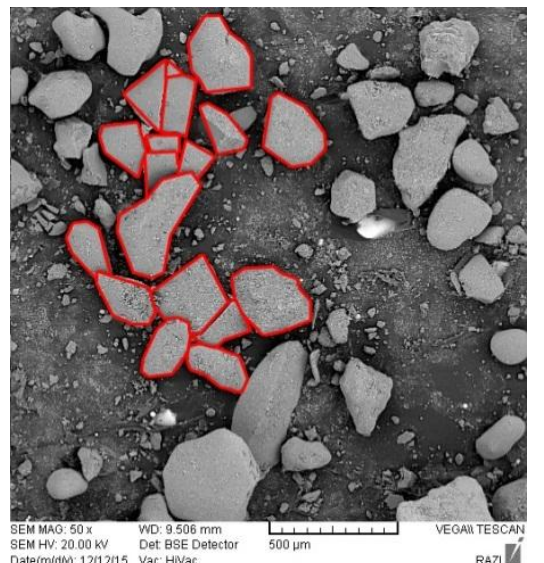

Sample 2

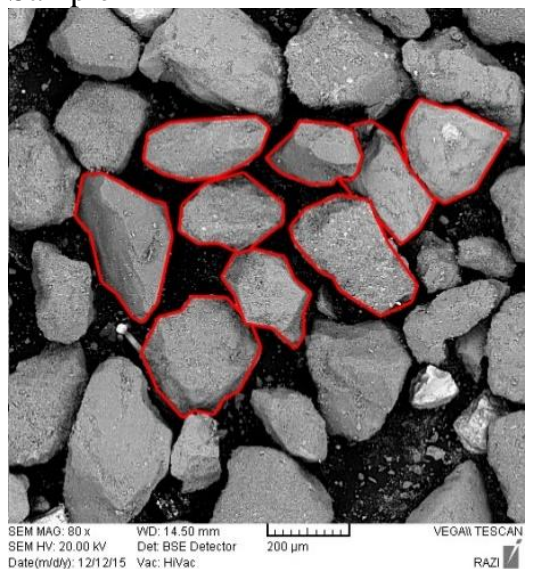

Sample 5

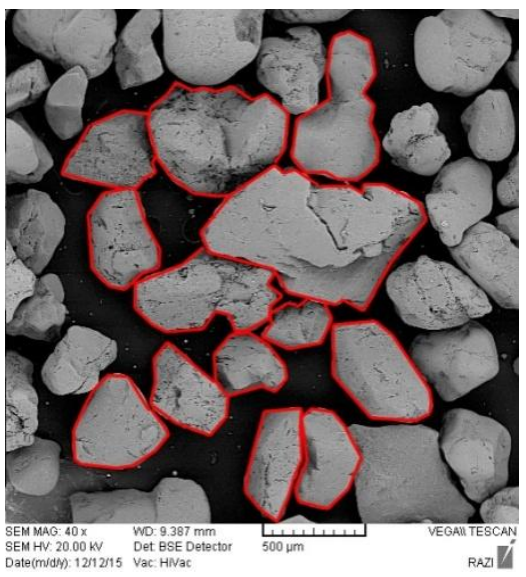

Sample 3

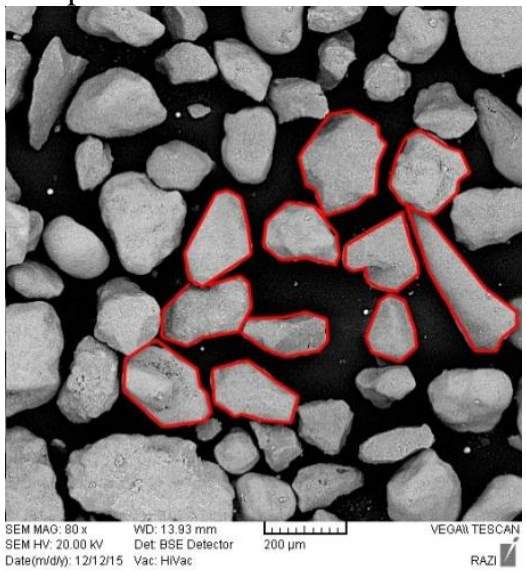

Sample 6

Sample 7

Figure 6. Microscopic images of samples

The roundness test is related to the degree of angularity of the particles. The output of this test is the roundness coefficient, which ranges from 0.0 to 1.0. Roundness can be quantified as the average radius of curvature of surface features relative to the radius of the maximum sphere that can be inscribed in the particle. Roughness describes the surface texture relative to the radius of the particle (10). The results of the roundness test on sand samples are presented in Table 6.

Sphericity indicates whether one, two, or three of the particle dimensions are of the same order of magnitude; it is defined as the diameter 
of the largest inscribed sphere relative to the diameter of the smallest circumscribed sphere (10). The results of the sphericity test are presented in Table 7.

Table 6. The results of roundness test

\begin{tabular}{cc}
\hline & Roundness \\
\hline Sample 1 & 0.2 \\
Sample 2 & 0.2 \\
Sample 3 & 0.1 \\
Sample 4 & 0.3 \\
Sample 5 & 0.4 \\
Sample 6 & 0.4 \\
Sample 7 & 0.6 \\
\hline
\end{tabular}

Table 7. The results of sphericity test

\begin{tabular}{lc}
\hline & Sphericity \\
\hline Sample 1 & 0.8 \\
Sample 2 & 0.7 \\
Sample 3 & 0.7 \\
Sample 4 & 0.8 \\
Sample 5 & 0.8 \\
Sample 6 & 0.8 \\
Sample 7 & 0.9 \\
\hline
\end{tabular}

A clear relationship is not observed between the results of the roundness and sphericity tests and the quality of sand samples used as beach soccer ground coverage, but particle shape parameters is used indirectly in the following steps for the purpose of sand ranking. The quality of sand on the beach soccer grounds mainly appears to be a function of the particle-size distribution (gradation).

Air moisture. The air moisture of the regions in which beach soccer grounds are located is another factor that can have an important impact on the behavior of sands. In fact, the moisture causes the sand to show a small degree of cohesiveness, because of linking between particles. It can change the quality of sand slightly. Therefore, the quality of a sand sample depends on not only the sand properties but also regional conditions. The regional moisture levels for seven sand samples are shown in Table 8.
Numerical simulations. To examine the results mentioned in the previous sections, a 2D numerical model of particles is established using Discrete Element Method (DEM). Using the DEM model, a number of simulations are conducted, through which the effect of gradation and particle shapes is studied. A special test is simulated using the numerical model to study the effect of gradation and particle shapes (Figure 7).

Table 8. Regional average air moisture

\begin{tabular}{cc}
\multicolumn{2}{c}{ (weatherspark.com) } \\
\hline & Moisture (\%) \\
\hline Sample 1 & 0.74 \\
Sample 2 & 0.49 \\
Sample 3 & 0.76 \\
Sample 4 & 0.70 \\
Sample 5 & 0.29 \\
Sample 6 & 0.56 \\
Sample 7 & 0.51 \\
\hline
\end{tabular}

In the past section, it is shown that the most important factor that affects sand quality is the gradation or particle size distribution. The numerical simulations are conducted in two parts. Firstly, the effect of gradation is investigated and then the impact of friction coefficient as a consequence of particle shape is studied.

The numerical tests program is shown in Table 9. The particle assemblages in Simulations 1 to 5 have different gradations, with varying maximum and minimum particle sizes. Therefore, they are expected to show different behaviors. In Simulations 6-10, different friction coefficients are selected to study the effect of particle shape. It should be noted that in all simulations, the particles are circular for the purpose of simplicity, though the friction coefficient is used as a consequence of the particle shape.

The energy used in Tests 1-5 for $20.0 \mathrm{~mm}$ of penetration is shown in Figure 8. The presented diagrams are related to Simulation 1-5 with different gradations. It can be seen that the samples with different gradations show different energy-displacement diagrams. 
Therefore, gradation can affect the sand behavior.

The energy for $20.0 \mathrm{~mm}$ of penetration for Tests 6-10 is presented in Figure 9. The samples have identical gradations with different friction coefficients. It is observed that the samples with different friction coefficients show different energydisplacement responses. It seems that the friction coefficient has an effect on sand quality, but it is not as significant as that of gradation.
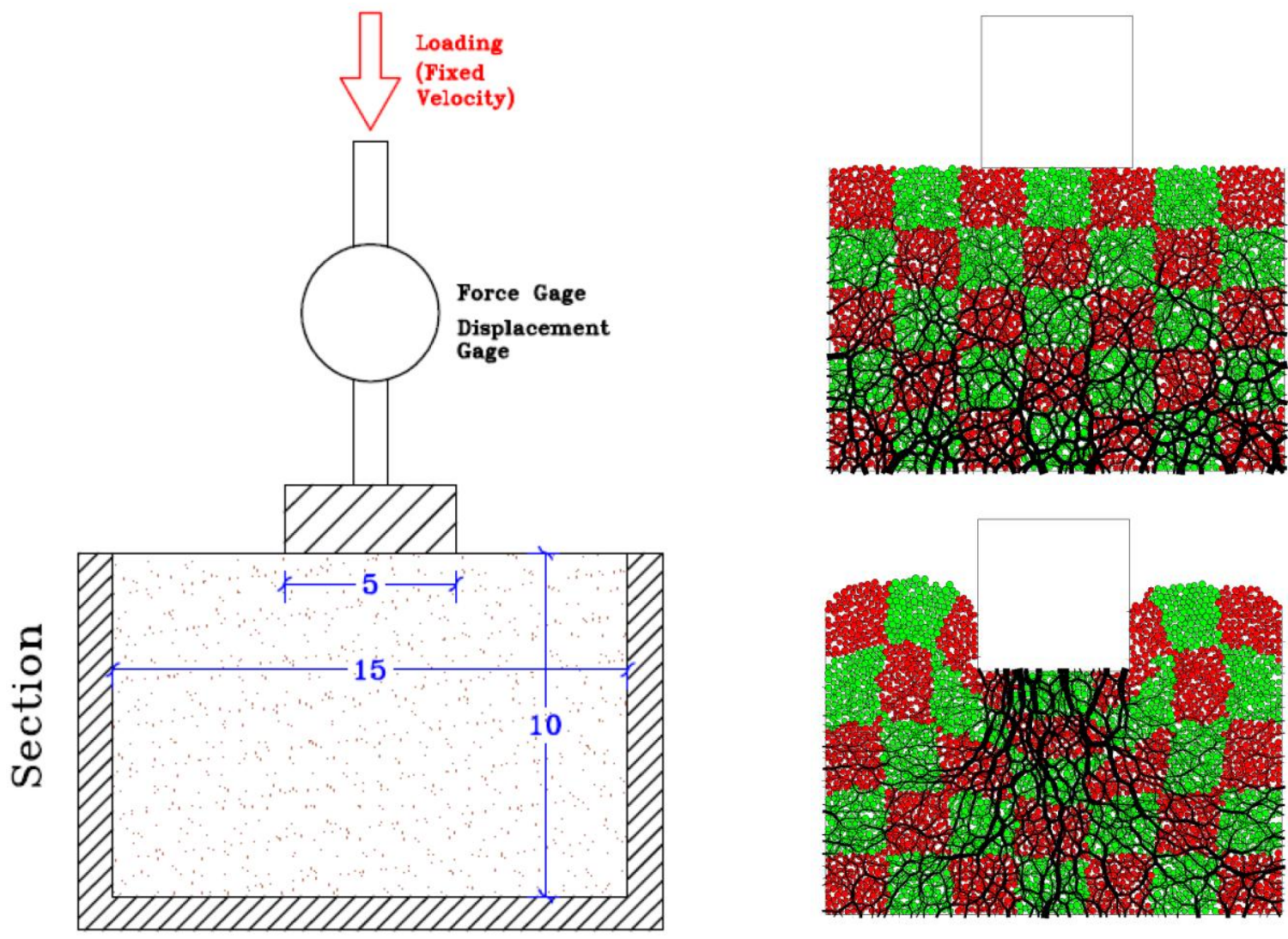

Figure 7. Numerical model using DEM

Table 9. Numerical tests program.

\begin{tabular}{ccccc}
\hline Simulation No. & Average Size $(\mathrm{mm})$ & Min. Size $(\mathrm{mm})$ & Max Size $(\mathrm{mm})$ & Fiction Coeff. \\
\hline 1 & 2.0 & 1.8 & 2.2 & 0.05 \\
2 & 2.0 & 1.6 & 2.4 & 0.05 \\
3 & 2.0 & 1.4 & 2.6 & 0.05 \\
4 & 2.0 & 1.2 & 2.8 & 0.05 \\
5 & 2.0 & 1.0 & 3.0 & 0.05 \\
\hline 6 & 2.0 & 1.8 & 2.2 & 0.06 \\
7 & 2.0 & 1.8 & 2.2 & 0.07 \\
8 & 2.0 & 1.8 & 2.2 & 0.08 \\
9 & 2.0 & 1.8 & 2.2 & 0.09 \\
10 & 2.0 & 1.8 & 2.2 & 0.10 \\
\hline
\end{tabular}




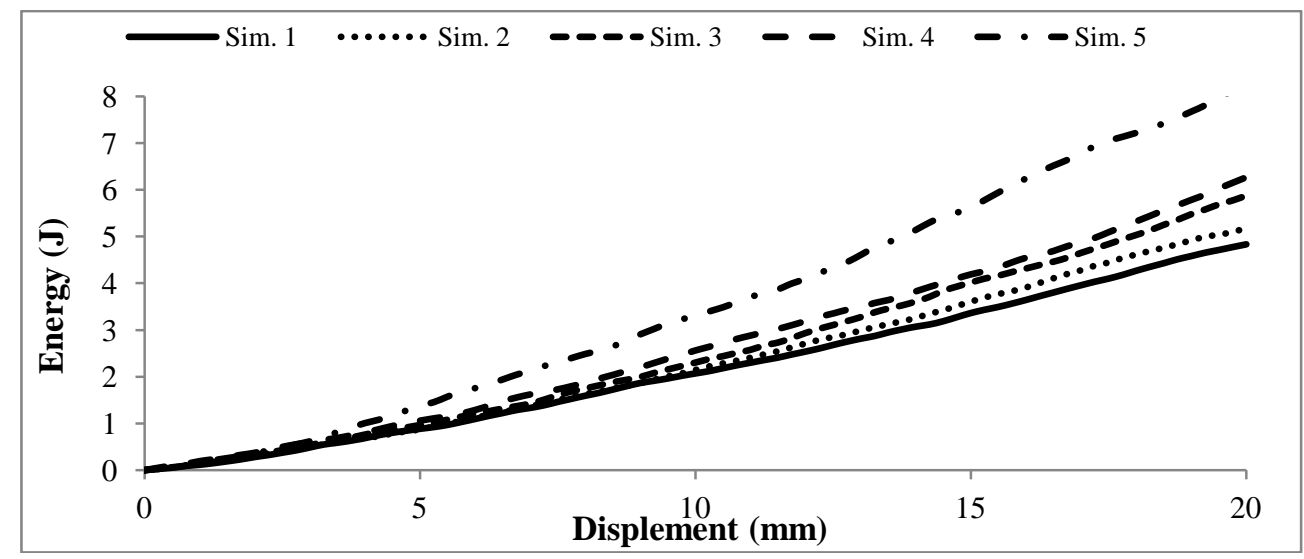

Figure 8. Energy vs. displacement (various gradations)

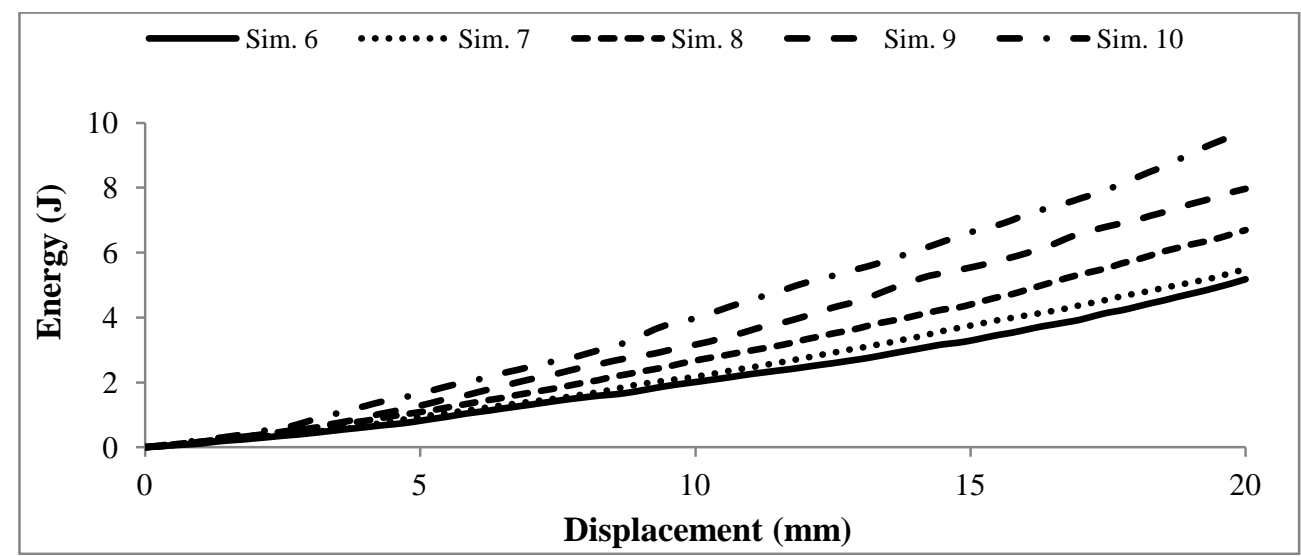

Figure 9. Energy vs. displacement (various friction coefficients)

Proposed ranking method. All tests mentioned in the previous sections are conducted to investigate the effective parameters for the selection of an appropriate sand type to cover a beach soccer ground. The methods presented here can be used to rank different sand samples, to evaluate them in terms of coverage of beach soccer grounds, and to standardize the beach soccer grounds. After analyzing all gathered data of sand samples and regional conditions, it was decided that among all of them, the gradation and roundness test results and the average air moisture can be used to simply and effectively predict the quality of sand to be used for the coverage of beach soccer grounds.

Two parameters (A and B) are calculated from gradation data (Table 5) according to Equations 2 and 3, where $\operatorname{Dia}(\max )$ is the maximum number in each row in Table 5.

$$
\begin{aligned}
& A=|0.62 \operatorname{Dia}(\max )-\operatorname{Dia}(20 \%)| \\
& B=|0.66 \operatorname{Dia}(\max )-\operatorname{Dia}(30 \%)|
\end{aligned}
$$

All selected parameters to be used in the proposed ranking equation are shown in Table 10. The calculated values of these parameters for seven sand samples are shown in Table 11.

Table 10. Selected parameters for sand ranking formula

\begin{tabular}{ccc}
\hline Parameter & Definition & Unit \\
\hline $\mathrm{A}$ & Equation 2 & $\mathrm{mm}$ \\
$\mathrm{B}$ & Equation 3 & $\mathrm{mm}$ \\
$\mathrm{C}$ & Dia.(50\%) , Table 4, Table 6 & $\mathrm{mm}$ \\
\cline { 2 - 3 } $\mathrm{D}$ & Roundness & \\
$\mathrm{E}$ & Dia. (90\%), Table 4 & $\mathrm{mm}$ \\
\hline
\end{tabular}


Table 11. Values of selected parameters

\begin{tabular}{lccccc}
\hline & $\mathrm{A}$ & $\mathrm{B}$ & $\mathrm{C}$ & $\mathrm{D}$ & $\mathrm{E}$ \\
\hline Sample 1 & 0.014 & 0.009 & 0.881 & 0.274 & 0.74 \\
Sample 2 & 0.093 & 0.021 & 2.118 & 1.679 & 0.49 \\
Sample 3 & 0.083 & 0.135 & 6.501 & 1.641 & 0.76 \\
Sample 4 & 0.024 & 0.131 & 1.336 & 1.337 & 0.70 \\
Sample 5 & 0.021 & 0.053 & 0.510 & 0.275 & 0.29 \\
Sample 6 & 0.129 & 0.046 & 0.460 & 0.545 & 0.56 \\
Sample 7 & 0.041 & 0.057 & 0.554 & 0.889 & 0.51 \\
\hline
\end{tabular}

Equation 6 is the suggested ranking formula resulting from this study. This formula accurately covers the scores of all seven sand samples according to the players' survey. Using this formula, a score can be determined that shows the quality of each sand sample for the purpose of using it to cover the beach soccer ground. The results for the proposed ranking method for seven sand samples are presented in Figure 10. It is obvious from the presented data that Equation 4 can predict the scores of sand samples successfully, with an error close to zero.

$$
S=8.67-25.56 A-5.22 B-0.45 C+0.98 D+0.62 E
$$
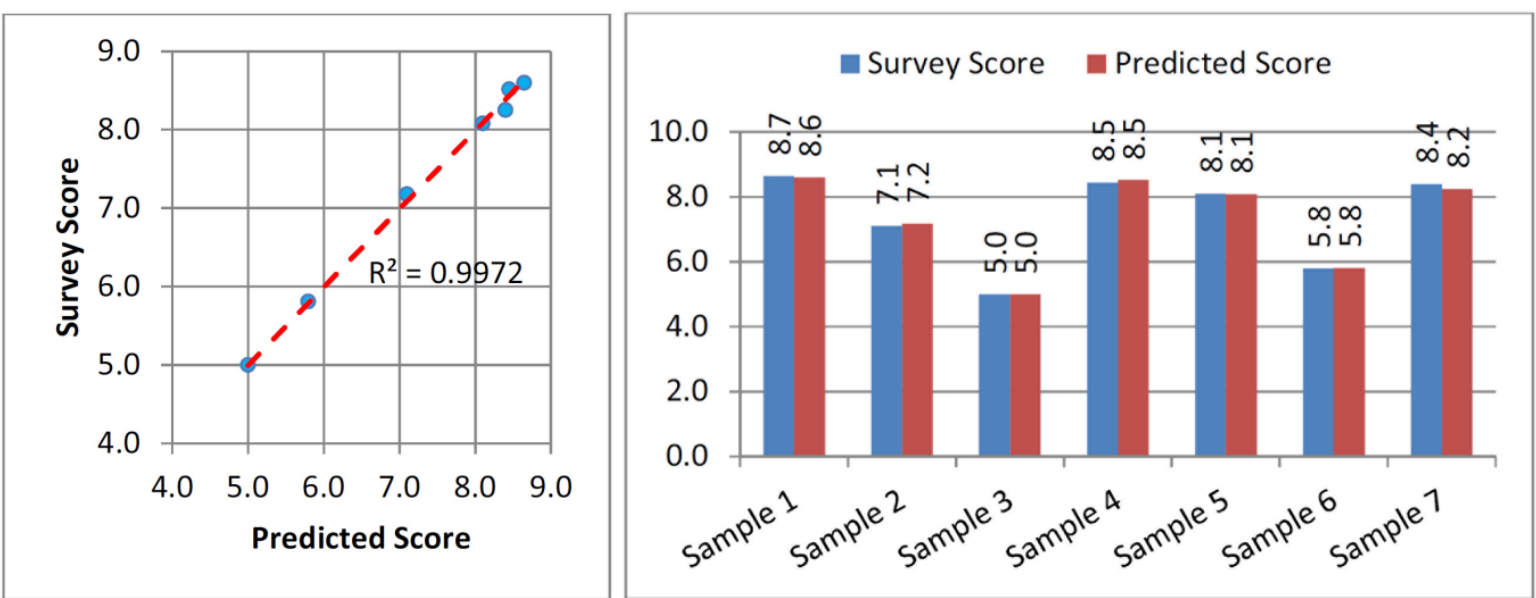

Figure 10. Predicted score vs. survey score

\section{DISCUSSION AND CONCLUSION}

Beach soccer is one of the most well-known international sports in the world. In this study, an investigation is conducted to identify the effective parameters of beach soccer sand that affect the acceptability and quality of sand. The aim of this study is to determine which type of sand is more in accordance with the expectations of beach soccer players. A method for ranking and standardization of beach soccer grounds is also introduced.

According to the results of this study, the following conclusions can be made.

○ The gradation diagrams of high-, medium-, or low-quality sand samples have some substantial differences.

- A high-quality sand sample has a bell-shaped gradation diagram (scaled), with its maximum point in the middle region of the diagram.
- The gradation diagram of low-quality sands is not bell-shaped or smooth enough, or its maximum point is not in the middle area of the diagram.

- According to the numerical simulations, it can be said that gradation and particle shape are two effective factors that determine the sand quality.

○ In this study, after conducting several tests, surveys, and regional data collection, a simple and reliable method for ranking the sand types used for beach soccer ground coverage is presented. The method can accurately predict the score of each sand sample using the input data of gradation test and roundness test, as well as regional data (average air moisture).

- According to the level of the match, a score for sand can be specified. In this manner, the beach soccer grounds can be standardized 
using the presented ranking method. The authors suggest a score according to the presented ranking method for each level of the beach soccer match (Table 12).

Table 12. Suggested sand quality vs. match level

\begin{tabular}{cc} 
Level of match & Suggested sand quality \\
World cup & $\mathrm{S} \geq 8$ \\
Continental & $\mathrm{S} \geq 7$ \\
National & $\mathrm{S} \geq 6$ \\
Regional & $\mathrm{S} \geq 5$ \\
Training & $\mathrm{S} \geq 3$ \\
Inacceptable & $\mathrm{S}<3$ \\
\hline
\end{tabular}

\section{PATENT}

After conducting a comprehensive investigation of the different properties of beach sand, gathering regional data, and doing a survey, a number of parameters are selected, which have the most effect on sand quality. These parameters are extracted from sand gradation diagrams, particle shape, and average regional moisture. Using these parameters, a procedure is introduced to determine sand quality and to standardize beach soccer grounds according to the level of beach soccer matches.

The suggested procedure of determining sand quality is patented with the title "Sand ranking procedure to evaluate beach soccer ground coverage" under patent registration No. 90559, Date 2016-12-03 in Real Estate Registration Organization of Iran. In the following paragraphs, the main parts of this patent registration certificate are explained in brief.

Title of the invention. Sand ranking procedure to evaluate beach soccer ground coverage

Technical field. Science (Geotechnics), Sport

Definition of the problem to be solved and aims of the invention. In this section, the existing problems related to sand quality determination and standardization of beach soccer grounds are explained.

The situation of existing knowledge related to the subject of the invention. In this section, the existing criteria for the selection of an appropriate sand type according to FIFA guidelines are mentioned.

Suggestion of the solution to the technical problem with a detailed explanation. In this section, the concept of sand quality, or "S" parameter (Equation 4), is explained. The bases and steps through which this parameter is developed are mentioned. After that, according to the level of beach soccer matches, a minimum sand quality is suggested (Table 12) on the basis of the personal experiences of the inventor in his role as an international beach soccer referee.

Explanation of figures, drawings and diagrams. In this part, the steps to calculate the needed parameters needed to determine sand quality (S) formula (Parameters A, B, C, D, and $\mathrm{E}$ in Table 10) are first explained in detail and then the sand quality formula is introduced (Equation 4).

$S=8.67-25.56 A-5.22 B-0.45 C+0.98 D+0.62 E$

(4)

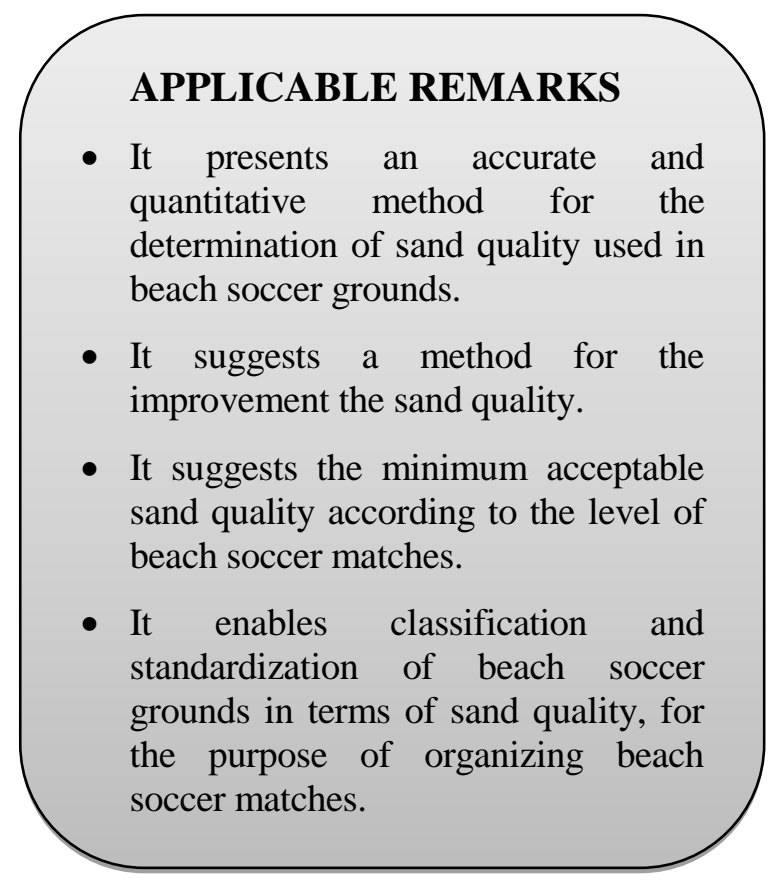

\section{REFERENCES}

1. Casamichana D, Castellano J. Time-motion, heart rate, perceptual and motor behaviour demands in small-sides soccer games: effects of pitch size. Journal of sports sciences. 2010;28(14):1615-23.

2. FIFA Beach Soccer Committee. BEACH SOCCER, Laws of the Game, 2015/2016. Zurich, Switzerland: Fédération Internationale de Football Association,,. 160 p. 
3. Martins L, Barboza E. Sand-gravel marine deposits and grain-size properties. Gravel. 2005;3:59-70.

4. Arasan S, Akbulut S, Hasiloglu AS. Effect of particle size and shape on the grain-size distribution using Image analysis. International journal of civil and structural engineering. 2011;1(4):968-85.

5. Han X, Kuroda T, Tatsuoka F, Kiyota T. Influence of particle size and geometry on the pullout tests of geocell embedded in soil. Bulleting of Earth Resistance Structures. 2012;45:159-68.

6. Frossard E. Effect of sand grain shape on interparticle friction; indirect measurements by Rowe's stress dilatancy theory. Géotechnique. 1979;29(3):341-50.

7. Salimi N, Yazdanjou V, Hamidi A, editors. Shape and size effects of gravel grains on the shear behavior of sandy soils. Proceedings of 10th Int Conf on Landslides and Engineered Slopes, Chen et al (eds), China; 2008.

8. Mostefa Kara E, Meghachou M, Aboubekr N. Contribution of particles size ranges to sand friction. Engineering, Technology \& Applied Science Research. 2013;3(4):497-501.

9. McDowell GR, Bolton MD. Effect of particle size distribution on pile tip resistance in calcareous sand in the geotechnical centrifuge. Granular Matter. 2000;2(4):179-87.

10. Cho G-C, Dodds J, Santamarina JC. Particle Shape Effects on Packing Density, Stiffness, and Strength: Natural and Crushed Sands. Journal of Geotechnical and Geoenvironmental Engineering. 2006;132(5):591-602.

11. Ebinuma T, Kamata Y, Minagawa H, Ohmura R, Nagao J, Narita H, editors. Mechanical properties of sandy sediment containing methane hydrate. Proceedings of Fifth International Conference on Gas Hydrates, Pap; 2005.

12. Mitachi T. Mechanical Behavior of Bentonite-Sand Mixtures as Buffer Materials. Soils and Foundations. 2008;48(3):363-74.

13. Dixon DA, Gray MN, Thomas AW. A study of the compaction properties of potential clay — sand buffer mixtures for use in nuclear fuel waste disposal. Engineering Geology. 1985;21(3):247-55.

14. Gray M, Cheung S, Dixon D. The influence of sand content on swelling pressures and structure developed in statically compacted Na-bentonite. Atomic Energy of Canada Ltd.; 1984.

15. Lingnau BE, Graham J, Yarechewski D, Tanaka N, Gray MN. Effects of temperature on strength and compressibility of sand-bentonite buffer. Engineering Geology. 1996;41(1):103-15.

16. Oswell JM. Elastic plastic behaviour of a sand-bentonite mixture 1991.

17. Asghari E, Toll DG, Haeri SM. Triaxial behaviour of a cemented gravely sand, Tehran alluvium. Geotechnical \& Geological Engineering. 2003;21(1):1-28.

18. Clough GW, Sitar N, Bachus RC, Rad NS. Cemented sands under static loading. Journal of Geotechnical and Geoenvironmental Engineering. 1981;107(ASCE 16319 Proceeding).

19. Consoli NC, Prietto PDM, Ulbrich LA. Influence of Fiber and Cement Addition on Behavior of Sandy Soil. Journal of Geotechnical and Geoenvironmental Engineering. 1998;124(12):1211-4.

20. Coop M, Atkinson J. The mechanics of cemented carbonate sands. Geotechnique. 1993;43(1):53-67.

21. Dupas J, Pecker A. Static and dynamic properties of sand-cement. Journal of the Soil Mechanics and Foundations Division. 1979;105(3):419-36.

22. Haeri SM, Hosseini SM. A comparison of drained tests on wet and saturated cemented sandy gravel. Tehran, Iran: Sharif University of Technology; 2003.

23. Haeri SM, Hosseini SM, Toll DG, Yasrebi SS. The behaviour of an artificially cemented sandy gravel. Geotechnical \& Geological Engineering. 2005;23(5):537-60.

24. Hamidi A, Haeri SM, Tabatabaee N, editors. Influence of gypsum cementation on the shear behavior of cemented sands. 1st National Congress on Civil Engineering; 2004; Tehran, Iran: Sharif University of Technology.

25. Huang JT, Airey DW. Properties of Artificially Cemented Carbonate Sand. Journal of Geotechnical and Geoenvironmental Engineering. 1998;124(6):492-9.

26. Saxena SK, Lastrico RM. Static properties of lightly cemented sand. Journal of Geotechnical and Geoenvironmental Engineering. 1978;104(ASCE 14259):1449-64.

27. Schnaid F, Prietto PDM, Consoli NC. Characterization of Cemented Sand in Triaxial Compression. Journal of Geotechnical and Geoenvironmental Engineering. 2001;127(10):857-68.

28. Cornforth DH. Some Experiments on the Influence of Strain conditions on the Strength of Sand. Géotechnique. 1964;14(2):143-67.

29. De Beer E, editor Bearing capacity and settlement of shallow foundations on sand. Proc of Symp Bearing Capacity and Settlement of Foundation; 1965.

30. Thevanayagam S, Ravishankar K, Mohan S. Steady-State Strength, Relative Density, and Fines Content Relationship for Sands. Transportation Research Record: Journal of the Transportation Research Board. 1996;1547:61-7.

31. Andersen GR, Swan CW, Ladd CC, Germaine JT. Small-strain behavior of frozen sand in triaxial compression. Canadian Geotechnical Journal. 1995;32(3):428-51. 
32. Parameswaran VR, Paradis M, Handa YP. Strength of frozen sand containing tetrahydrofuran hydrate. Canadian Geotechnical Journal. 1989;26(3):479-83.

33. Ting JM, Martin RT, Ladd CC. Mechanisms of Strength for Frozen Sand. Journal of Geotechnical Engineering. 1983;109(10):1286-302.

34. Ladd RS. Specimen preparation and liquefaction of sands. Journal of Geotechnical and Geoenvironmental Engineering. 1974;100(10):1180-4.

35. Lade PV, Yamamuro JA. Effects of nonplastic fines on static liquefaction of sands. Canadian Geotechnical Journal. 1997;34(6):918-28.

36. Mancuso C, Vassallo R, d'Onofrio A. Small strain behavior of a silty sand in controlled-suction resonant column [? torsional shear tests. Canadian Geotechnical Journal. 2002;39(1):22-31.

37. Mulilis JP, Arulanandan K, Mitchell JK, Chan CK, Seed HB. Effects of sample preparation on sand liquefaction. Journal of the Geotechnical Engineering Division. 1977;103(2):91-108.

38. Crum JR, Wolff TF, Freeborn RA, Miller M, editors. Engineering Properties of High Sand Content Soils Used in Golf Putting Greens and Sports Fields. 67th Annual Michigan Turfgrass Conference; 1997 January 20-24, 1997; Lansing, MI: Michigan State University Extension.

39. ASTM F2396-11, , , , , www.astm.org. Standard Guide for Construction of High Performance Sand-Based Rootzones for Athletic Fields. West Conshohocken, PA: ASTM International; 2011.

40. Barrett PJ. The shape of rock particles, a critical review. Sedimentology. 1980;27(3):291-303.

41. Folk RL. Student operator error in determination of roundness, sphericity, and grain size. Journal of Sedimentary Research. 1955;25(4):297-301.

42. Krumbein WC, Freeman WH, Sloss LL. Stratigraphy and Sedimentation. Second ed. San Francisco: W. H. Freeman \& Co.; 1963. 497 p. 